\title{
Indications and Outcome of Admission of Patients with Diabetes into Benha University Hospitals, Egypt: A Prospective Study
}

Amira M. Elsayed, Ayman M Elbadawy, Walla M. lbrahim, Marwa S. Mahfoz, Rasha O. Abd Elmoniem,

\begin{abstract}
Department of internal medicine, Benha faculty of medicine, Benha University, Egypt.

Correspondence to: Amira M. Elsayed, Department of internal medicine, Benha faculty of medicine, Benha University, Egypt.

Email:

amiramohamady@gmail.com

Received: 9 November 2020

Accepted: 22 March 2021

Background: Patients with diabetes have a 3-fold greater chance of hospitalization compared to those without diabetes. The risk factors for hospitalizations in diabetic patients constitute poor glycemic control, longer diabetes duration, and coexisting morbidity. Other factors include, old age groups, insulin use, hypoglycemia, presence of chronic renal insufficiency and diabetes-related hospitalizations in the preceding year are other important risk factors. Aim: Our aim of the study is to report the causes, patient characteristics, and outcome of admissions of diabetic patients to the wards and emergency unit of Benha university hospital Methods: The study included 260 patients with known history of type 1 or $2 \mathrm{DM}$ who were admitted from the emergency department, outpatient clinic , and other departments of the hospital.Demographic data and laboratory investigations were collected. Results: The study constituted mainly type 2DM (90.4\%). The mean age of the study population was $57 \pm 14$ years, most of them were females (55.8\%).The median duration of diabetes was 10 years.The most common reason for diabetes related hospitalizations were chronic complications of DM, whereas sepsis is the most common reason of non diabetes related .The mortality rate was $26.9 \%$, of overall deaths, cardiovascular disease was the most frequent( 47.7\%).Conclusion: The most frequent reason for hospitalization in diabetic related admissions was chronic complications of diabetes. Whereas, sepsis is the most common cause in diabetic non related admissions.Cardiovascular disease is still the main cause of death among diabetics.
\end{abstract}

Key words: Outcome; Diabetes; Hospitalization. 


\section{Introduction:}

Diabetes is a prevalent metabolic syndrome that affects more than 415 million people globally (1). Diabetes is a costly situation associated with substantial levels of morbidity and mortality (2). Even more, patients with diabetes have a 3-fold greater chance of hospitalization compared to those without diabetes (3). It is estimated that more than $20 \%$ of all adults discharged have diabetes, with $30 \%$ of them necessitating 2 or more hospitalizations per year (3), and (4).

The care of patients with diabetes carry out a considerable burden on the economy, with a total estimated cost of diagnosed diabetes in the United States in 2012 was $\$ 176$ billion in medical care. The largest component of this medical expenditure is hospital inpatient care, accounting for $43 \%$ of the total medical cost (5). The most frequent diabetes-related hospitalizations were related to renal failure (33.6\%), hypertension $(12,6 \%)$ and cataract $(12 \%)$, whilst for non-diabetes-related hospitalizations, atherosclerotic heart disease (3.1\%), anemia (1.7\%), and 'unspecified' illness (1.4\%) were most frequently stated (6).

Patients with T2D have a greater risk of vascular complications including cardiovascular (CV) morbidity and mortality (7) and are twice as likely to be hospitalized with a longer hospital stays (8) and (9). The risk factors for hospitalizations in diabetic patients constitute poor glycemic control, longer diabetes duration, and coexisting morbidity (10). In addition, old age groups, insulin use, hypoglycemia, presence of chronic renal insufficiency and diabetes-related hospitalizations in the preceding year are other important risk factors for hospitalization (6). In patients with type 1 DM, hospital admission for DKA and severe hypoglycemia may be influenced by age, sex, diabetes duration, ethnic origin (11) and, insulin treatment regimen (use of insulin pump or multiple daily insulin injections) (12). Patients hospitalized with a diagnosis of diabetes stay in the hospital for longer than those without a diagnosis of diabetes admitted for the same condition (13). A large proportion of hospitalizations for diabetes are avoidable by improvements in the quality of primary care outpatients clinics for diabetes (14).

So, our aim of the study was to investigate the indications and outcome of admissions of diabetic patients to the hospital for proper care of diabetics in hospitals and if these admissions can be prevented or not. Identification of hospitalization of patients with diabetes and who may be managed as 
outpatients is important in reducing healthcare costs.

\section{Aim of the work:}

The aim of our study is to report the causes of admissions of diabetic patients to medical wards and emergency unit of Benha university hospital, and to determine the demographic characteristics of the patients, different risk factors, outcome, and duration of the hospital stay.

\section{Patient and method:}

This is a prospective descriptive hospital based study of patients with diabetes admitted into the medical wards and emergency unit of Benha University Hospital, in Egypt over a six months period from October 2019 to April 2020.

The study included 260 patients with known history of type 1 or $2 \mathrm{DM}$ who were admitted from the emergency department, the medical out-patient department, and the patients transferred into medical wards from the other departments of the hospital.

Patients without a known history of diabetes, and with pregnancy were excluded. Approval for the study was obtained from the Ethics Committee of Benha Univeristy. Relevant data (age, gender, diagnosis, indications of admission, risk factors, treatment, duration of hospital stay and outcome) were extracted from the case files of patients, and from the records department of the hospital in conjunction with ward admissions discharge logs and accident emergency records. Laboratory investigations $(\mathrm{CBC}$, renal function tests, urine analysis, HbA1c, TSH, serum cholesterol, serum $\mathrm{Na}$, serum K, FBG, 2hPPBG, CRP, albumin, $24 \mathrm{~h}$ urinary albumin) of the patients were done in the clinical pathology department of Benha university Hospital according to the local routine methods. Good glycemic control was defined as $\mathrm{HbA} 1 \mathrm{c} \leq 7.5 \%$ and bad glycemic control $>7.5 \%$. The indications for admitting diabetic patients were broadly classified into non-diabetes-related and diabetes-related. Diabetes-related indications were further classified into acute metabolic emergencies and chronic complications of diabetes mellitus. Acute emergent conditions included diabetic ketoacidosis, hyper osmolar non ketotic states, hypoglycemia, uncontrolled hyperglycemia (in either type of diabetes).

While, severe chronic complications of diabetes that require intensive treatment included microvascular complications (diabetic nephropathy) and macrovascular complications (diabetic foot, MI, stroke related to DM). The outcome of the hospitalization was recruited, including improvement of the condition, the mortality rate of the hospitalized patients and the causes of death. 


\section{Statistical analysis:}

The statistical analyses were completed using SPSS (Statistical Package for Social Science) version 16. The data were expressed as number percentages, means \pm standard deviation (SD), and median and inter-quartile range (IQR). As regards the normally distributed (parametric) quantitative data, the means and standard deviations were used and $\mathrm{P}$ values of less than $0.05(\mathrm{P}<0.05)$ are considered significant. While, the non parametric data were presented as median and inter-quartile range (IQR).

\section{Results}

The mean age of the study population was $57 \pm 14$ years. Males were $44.2 \%$, while females $55.8 \%$ of the study population. The median duration of diabetes was 10 years ( IQR; 0.5 to 35 years), most of them were type 2DM (90.4\% ). In terms of treatment of diabetes, $32.7 \%$ received insulin, $34.6 \%$ received $\mathrm{OAD}$, while the remaining $32.7 \%$ shifted from OAD to insulin. The patients who were admitted to the ICU were $51.9 \%$, while those admitted to the ward were $48.1 \%$.

The medication used during the hospitalization included, basal-bolus insulin regimen $67.3 \%$ of patients, insulin infusion $30.8 \%$ of patients, and only $1.9 \%$ received glucose $25 \%$ continuous infusion (table 1 ). In terms of laboratory findings(table 2); the median WBCs was $4.9 \times 10^{9} / \mathrm{L}$ ( IQR; 2.9$35)$, and the mean $\mathrm{HB}$ value was 10.7 $\mathrm{gm} / \mathrm{dl}(\mathrm{SD} ; \pm 1.7)$. The median creatinine was $2 \mathrm{mg} / \mathrm{dl}$ (IQR; 0.1 to 9 ).

Abnormal Pus cells in urine were seen in $51.9 \%$ of the admitted patients. The glycemic control parameters were as follows; the mean $\pm \mathrm{SD}$ of $\mathrm{HbA} 1 \mathrm{c}$, FBG,PPBG were $9.1 \pm 1.2 \%, 265 \pm 66$ $\mathrm{mg} / \mathrm{dl}, \quad 338 \pm 86 \mathrm{mg} / \mathrm{dl}$ respectively. The median CRP was 48mg/L( IQR; 3.2 to 125 ). In terms of the causes of admission (table 3)(figure 1), all diabetes related admission were $73.9 \%$ of the study populations; acute complications of diabetes were $23.1 \%$ of the cases with DKA as the most frequent cause of admission (13.5\%), followed by uncontrolled hyperglycemia $(7.7 \%)$ then hypoglycemia (1.9\%).

The prevalence of chronic complications of diabetes was $50.8 \%$ of the cases, including diabetic nephropathy (32.7\%), diabetic foot (9.6\%), MI (7.7\%), and stroke related to DM $(0.8 \%)$. The diabetes non related admissions accounted for $47.3 \%$ of all admissions, including sepsis (28.8\%), non diabetic nephropathy $(7.7 \%)$, stroke related to other causes $(7.7 \%)$, arrhythmia (6.9\%), emergency HTN (1.9\%), and PE (1.2\%). The outcome of hospitalization was summarized in table (4); most of the study population showed improvement (73.1\%) 
meanwhile $26.9 \%$ died for different reasons including; septic shock (23.1\%), cardiogenic shock (20\%), uremic complication (18.5\%), myocardial infarction (12.3\%), DKA (10.8\%), PE (7.7\%), stroke (4.6\%), and rapid $\mathrm{AF}(3.1 \%)$ (table 5). The patients with worse glycemic control were $60.8 \%$. The median length of stay was 7 days (IQR 1-30 days). Higher percent of patients were discharged on insulin therapy $(65.4 \%)$.

Table (1) General characteristic of study population.

\begin{tabular}{|c|c|c|}
\hline General characteristics & & \\
\hline -Age (years) & Mean \pm SD & $57 \pm 14$ \\
\hline \multirow[t]{2}{*}{-Gender. } & -Males & $115(44.2)$ \\
\hline & -Females & $145(55.8)$ \\
\hline Duration of DM (year) & Median (range) & $10(0.5-35)$ \\
\hline \multirow[t]{2}{*}{-Type of diabetes. } & $-\mathrm{T1DM}$ & $25(9.6)$ \\
\hline & $-\mathrm{T} 2 \mathrm{DM}$ & $235(90.4)$ \\
\hline \multirow[t]{3}{*}{-Treatment. } & -Insulin & $85(32.7)$ \\
\hline & $-O A D$ & $90(34.6)$ \\
\hline & -OAD shifted to insulin & $85(32.7)$ \\
\hline \multirow[t]{2}{*}{-Site of admission. } & $-\mathrm{ICU}$ & $135(51.9)$ \\
\hline & -Ward & $125(48.1)$ \\
\hline \multirow[t]{2}{*}{-Operation. } & Yes & $70(26.9)$ \\
\hline & -Basal bolus insulin. & $175(67.3)$ \\
\hline \multirow{4}{*}{$\begin{array}{l}\text {-Medication for diabetes } \\
\text { during hospitalization. }\end{array}$} & -Glucose $25 \%$ continuous infusion. & \\
\hline & -Insulin infusion & \\
\hline & & $5(1.9)$ \\
\hline & & $80(30.8)$ \\
\hline
\end{tabular}


Table (2): Laboratory findings of the study population.

\begin{tabular}{|c|c|c|}
\hline \multicolumn{3}{|l|}{ Laboratory findings } \\
\hline $\mathrm{HB}(\mathrm{gm} / \mathrm{dl})$ & Mean \pm SD & $10.7 \pm 1.7$ \\
\hline Platelets & Mean \pm SD & $276 \pm 131$ \\
\hline WBCs $\left(\times 10^{9} / \mathrm{L}\right)$ & Median (range) & $4.9(2.9-35)$ \\
\hline Urea $\left(\times 10^{9} / \mathrm{L}\right)$ & Median (range) & $54(10-228)$ \\
\hline Creatinine (mg/dl/) & Median (range) & $2(0.1-9)$ \\
\hline \multirow{5}{*}{ Urine analysis } & Free & $125(48.1)$ \\
\hline & Pus 20-25 & $10(3.8)$ \\
\hline & Pus 50 & $15(5.8)$ \\
\hline & Pus 8-10 cell & $10(3.8)$ \\
\hline & Pus over 100 & $100(38.5)$ \\
\hline HbA1c (\%) & Mean \pm SD & $9.1 \pm 1.2$ \\
\hline TSH (mIU/L) & Mean \pm SD & $1.76 \pm 0.93$ \\
\hline $\operatorname{AST}(\mathbf{U} / \mathbf{L})$ & Mean \pm SD & $19.4 \pm 6.6$ \\
\hline Cholesterol (mg/dl) & Mean \pm SD & $194 \pm 41$ \\
\hline $\mathrm{Na}(\mathrm{mEq} / \mathrm{L})$ & Mean \pm SD & $133 \pm 4$ \\
\hline $\mathrm{K}(\mathbf{m E q} / \mathbf{L})$ & Mean \pm SD & $3.6 \pm 0.4$ \\
\hline $\mathrm{CRP}(\mathrm{mg} / \mathrm{L})$ & Median (range) & $48(3.2-125)$ \\
\hline $\operatorname{Albumin}(\mathrm{g} / \mathrm{dl})$ & Mean \pm SD & $3.4 \pm 0.5$ \\
\hline FBG (mg/dl) & Mean \pm SD & $265 \pm 66$ \\
\hline PPBG (mg/dl) & Mean \pm SD & $338 \pm 86$ \\
\hline $24 \mathrm{hr}$ urinary albumin(mg) & Median (range) & $1.8(0.227-12)$ \\
\hline
\end{tabular}


Table (3) Causes of admission of the study group.

\begin{tabular}{lll}
\hline Diabetic related- Acute complications & $\mathrm{N}$ & $\%$ \\
\hline Hypoglycemia & 5 & 1.9 \\
HHS & 0 & 0 \\
DKAA & 35 & 13.5 \\
Uncontrolled hyperglycemia & 20 & 7.7 \\
Diabetes related chronic & & \\
complications & & \\
Diabetic Nephropathy & 85 & 32.7 \\
Diabetic foot & 25 & 9.6 \\
MI & 20 & 7.7 \\
Stroke related to DM & 2 & 0.8 \\
Non diabetic related & & \\
Non Diabetic nephropathy & 20 & 7.7 \\
Emergency HTN & 5 & 1.9 \\
Sepsis & 75 & 28.8 \\
Stroke related to other causes & 5 & 7.7 \\
PE & 3 & 1.2 \\
Arrhythmia & 18 & 6.9 \\
\hline & & \\
\hline & & \\
\hline
\end{tabular}

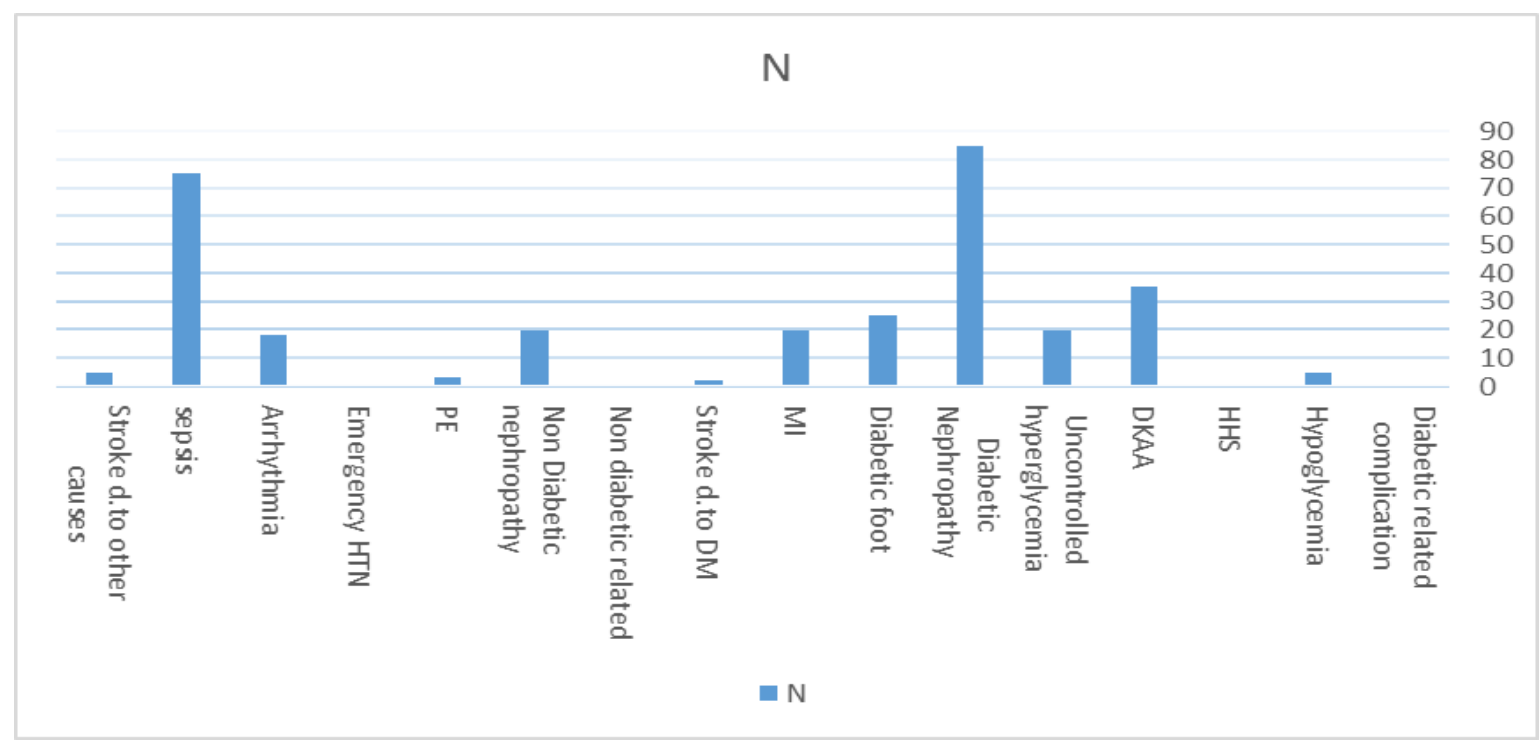

Figure (1): Causes of admission of the study group

Table (4): Outcome of the study group. 


\begin{tabular}{llll} 
Outcome & & $N$ & $\%$ \\
\hline Improvement & Yes & 190 & 73.1 \\
On discharge & Die & 70 & 26.9 \\
Treatment on discharge & Insulin & 170 & 65.4 \\
& OAD & 20 & 7.7 \\
Refer to other department & Yes & 40 & 15.4 \\
Glycemic control overall & Good & 102 & 39.2 \\
& Poor & 158 & 60.8 \\
Length of stay (days) & Median (range) & $7(1-30)$ & \\
\hline
\end{tabular}

Table (5) Causes of death among the admitted diabetics.

\begin{tabular}{llll}
\hline & & N & $\%$ \\
\hline Cardiogenic shock & Yes & 52 & 20.0 \\
Uremic complication & No & 208 & 80.0 \\
& Yes & 48 & 18.5 \\
PE & No & 212 & 81.5 \\
Myocardial infarction & Yes & 20 & 7.7 \\
& No & 240 & 92.3 \\
Rapid AF & No & 32 & 12.3 \\
& Yes & 228 & 87.7 \\
DKA & No & 252 & 3.1 \\
& Yes & 28 & 96.9 \\
Septic shock & No & 232 & 10.8 \\
& Yes & 60 & 89.2 \\
Stroke & No & 200 & 23.1 \\
& Yes & 12 & 76.9 \\
& No & 248 & $4.60 \%$ \\
\hline
\end{tabular}

\section{Discussion}


Several observational and trial data denoted that inpatient hyperglycemia, in patients with or without a prior diagnosis of diabetes, is connected to an increased risk of complications and mortality, a longer hospital stay, a higher admission rate to the intensive care unit (ICU), and a higher need for transitional or nursing home care after hospital discharge(4). The age of the study population ranged between 71 to 43 years with the mean age of $57 \pm 14$ years. In a similar fashion, one study showed the mean age of patients was $57 \pm 16$ years (15). The burden of diabetes is often described in terms of its influence on working-age adults, diabetes in older adults is linked to higher mortality, reduced functional status, and increased risk of hospitalization (16).

Since aging of the overall population is a substantial driver of the diabetes epidemic. In our study, the majority of the patients were females $(55.8 \%)$. This may be assigned to the fact that women are more obese with lack of physical activity than men (17). In contrast to another study which found that, $55.9 \%$ were males (15). In our study, almost $90 \%$ of the patients were Type 2DM consistent with Forouhi \& Wareham, who stated that type 2 diabetes constituted the majority $(>85 \%)$ of the overall diabetes prevalence (18). We observed that, of the 260 overall admissions, $135(51.9 \%)$ admissions were in the ICU and 125 $(48.1 \%)$ in the ward. Admission of diabetic patients in intensive care units (ICU) because of acute complications attributable to DM (diabetic ketoacidosis, hyperosmolar coma, and hypoglycemia), or some other underlying pathology and co-morbidity. The concomitant co-morbidities are the decisive factors responsible for such critical admissions and DM is a secondary contributor or sometimes an accidental finding (4) and (19).

In our study, $67.3 \%$ of patients received basal bolus. Moreover, $30.8 \%$ received an insulin infusion. The use of oral hypoglycemic agents is mostly not recommended in hospitalized patients due to limited data on their safety and efficacy and lack of flexibility in adjusting the dose in a harmony with the clinical status(20). Insulin is the best method to control hyperglycemia during hospitalization, especially in the critically ill patient. Intravenous insulin is the preferred method to achieve the recommended glycemic target (21). However, most of our patients received subcutaneous basal bolus. This explained by, Intravenous insulin may be suitable for people who are critically ill, people who are not eating and in those with hyperglycemia and metabolic decompensation e.g. DKA (22). Furthermore, in insulin-naive patients, there is evidence demonstrating the superiority of basal-bolus-correction insulin 
regimens (23). According to the ADA, intravenous insulin infusions should be administered based on validated written or computerized protocols that allow for adjustments in the infusion rate, glycemic fluctuations and insulin dose (24). Our results reported that most of our patients (65.4\%) used insulin therapy at discharge indicating worse glycemic control in $60.8 \%$ of them. The mean HbA1c was 9.1 (SD; 1.2) and The mean fasting blood glucose and $2 \mathrm{~h}$ postprandial were $265 \pm 66 \mathrm{mg} / \mathrm{dl}, 338$ $\pm 86 \mathrm{mg} / \mathrm{dl}$ respectively indicating uncontrolled hyperglycemia and necessitating insulin therapy. It is worth stating at this point that NICE guidelines recommend the use of insulin therapy if HbAlc is $75 \mathrm{mmol} / \mathrm{mol}(9.0 \%)$ or higher (25). All diabetes related admissions were almost $73.8 \%$, including $23.1 \%$ of acute complications (DKA is the most frequent of them), and $50.7 \%$ of them related to chronic complications of diabetes. Likewise, Al-adsani et al., reported that the most common reasons for hospitalizations in patients with diabetes was cardiovascular system diseases $(53.6 \%)$ including acute coronary syndrome, heart failure, and cerebrovascular accident, indicating the chronic complications of diabetes (2). Another study, demonstrated chronic complication as a main reason for hospitalization among elderly diabetics (26).
On the other hand, another study in Ethiopia found that diabetic ketoacidosis (DKA) was the commonest reason for hospitalization which attributed for admission of(33.7\%) patients followed by infections, (19.1\%), and cardiovascular diseases (CVDs), (18.0\% )( 27). The cause of this discrepancy as $74 \%$ of the patients in the Ethiopian study had type 1DM, while in our study more than $90 \%$ of the patients had type 2DM. Regarding diabetes non related admission, sepsis was the most common cause (28.8\%), followed by stroke not related to diabetes complications (7.7\%) (e.g; embolic and hemorrhagic cerebrovascular stroke) as well as non diabetes related nephropathy (7.7\%). On the contrary, one study revealed infection as the third most frequent reason for admission, responsible for $15.7 \%$ of diabetes non related hospitalizations (26). Our study found the mortality rate of $26.9 \%$ of the patients. Akirovel et al., revealed the hospital mortality risk was greater in patients with $\mathrm{DM}(\mathrm{aOR}=1.3,95 \% \mathrm{CI}=1.1$ 1.7) (28). Observational and prospective randomized clinical trials, in patients with and without diabetes, as well as in critically ill and non-critically ill patients have shown a strong relationship between hyperglycemia and poor clinical outcomes, such as mortality, infections and hospital complications (29) and (30). Patients with blood glucose levels >200 mg/dl (>11.1 
$\mathrm{mmol} / \mathrm{l})$ were shown to have higher mortality compared to those with blood glucose levels $<200 \mathrm{mg} / \mathrm{dl}(<11.1 \mathrm{mmol} /)$ $(5.0 \%$ vs. $1.8 \%, \mathrm{p}<0.001)$ (31). In fact, FBG \& PPBG were higher than $200 \mathrm{mg} / \mathrm{dl}$. Our study clarified that cardiovascular causes of death is the main reason for mortality, accounting $47.7 \%$ of deaths, and including; cardiogenic shock, pulmonary embolism, MI, stroke, and rapid AF. One must admit that, patients with T2D are at an increased risk of vascular complications including cardiovascular (CV) morbidity and mortality( 32). The rational of the injurious effects of hyperglycemia during acute illnesses are not completely understood. Current evidence indicates that severe hyperglycemia results in impaired neutrophil granulocyte function, high circulating free fatty acids, and overproduction of pro-inflammatory cytokines and reactive oxygen species (ROS) that can lead to direct cellular damage, and vascular and immune dysfunction (33). The median length of stay was 7 days (IQR; 1 - 30 d). It was suggested that type $2 \mathrm{DM}$ are twice as likely to be admitted to hospital with prolonged inpatient stays (32). Additionally, the severity of hyperglycemia correlates with the hospital stay (34). In a previous study, the duration of hospital stay ranged from 1 to 88 days, with a median duration 9 days. Other studies reported a range of 4.9 to
10.7 days (average of 8 days), and it was found the length of stay is higher than nondiabetic patients (35). The difference from one study to another may be related to the patient characteristics, underlying comorbidities and the prevalent diabetic complication.

\section{Conclusion}

This is a prospective descriptive study highlighted some of the characteristics of hospitalized diabetic patients. The most frequent reason for hospitalization in diabetic related admissions was chronic complications of diabetes. Whereas, sepsis is the most common cause in diabetic non related admissions. Cardiovascular disease still the main cause of death among diabetics. Factors that may have contributed to the decline in diabetes-related preventable hospitalizations include annual screening for complications of DM with proper management, using intervention with approved indications during hospitalizations, health education for diabetic patients, and immunizations against the commonest respiratory infections.

\section{Limitations of the study:}

Our study has three limitations; Firstly, we did not have a control group for comparison to identify the significant reason of admissions as well as the risk factors for admission in the study group. Secondly, we did not recruit the repeated admissions of the same patient to identify the indications 
and outcome. Thirdly, our results should stimulate further research with strong strategies for risk adjustment to clarify the association between diabetes and poor cardiac outcomes. While DM is a known risk factor for cardiovascular disease, with these results, future studies are required to determine whether improved blood glucose control in long and short term reduces the impact of diabetes on hospitalization outcome.

\section{Abbreviations:}

DM( diabetes mellitus).

DKA(diabetic ketoacidosis).

FBG(fasting blood glucose).

PPBG(postprandial blood glucose).

$\operatorname{ADA}($ American diabetes association).

OAD(oral antidiabetic drug).

ICU (internal care unit).

PE (pulmonary embolism).

MI(myocardial infarction).

$\mathrm{CV}$ (cardiovascular).

CBC(complete blood count).

HbA1c (glycosylated hemoglobin).

TSH(thyroid stimulating hormone).

IQR(inter-quartile range ).

SD (standard deviation).

HTN (hypertension).

\section{References:}

1. International Diabetes Federation. Diabetes Atlas, 7th edition. Brussels, Belgium:, 2015. Available from:

URL: http://www.idf.org/diabetesatlas. Accessed 2 June 2018.

2. Al-Adsani A.M.S., and Abdulla K.A. K.; Reasons for hospitalizations in adults with diabetes in
Kuwait.International Journal of Diabetes Mellitus.2015; 3(1):65-69.

3. Jiang HJ, Stryer D, Friedman B, Andrews R. Multiple hospitalizations for patients with diabetes. Diabetes Care. 2003 May; 26 (5): 1421 6. doi: 10.2337/dia care. 26.5.1421. PMID: 12716799.

4. Umpierrez GE, Isaacs SD, Bazargan N, You X, Thaler LM, Kitabchi AE . Hyperglycemia: an independent marker of in-hospital mortality in patients with undiagnosed diabetes. J Clin Endocrinol Metab. 2002 Mar; 87 (3): 978-82. doi: 10.1210/jcem. 87. 3. 8341. PMID: 11889147.

5. American Diabetes Association. Economic costs of diabetes in the U.S. in 2012. Diabetes Care. 2013 Apr; 36(4):1033-46. doi: 10.2337/dc122625. Epub 2013 Mar 6. PMID: 23468086; PMCID: PMC3609540.

6. Khalid JM, Raluy-Callado M, Curtis BH, Boye KS, Maguire A, Reaney M. Rates and risk of hospitalisation among patients with type 2 diabetes: retrospective cohort study using the UK General Practice Research Database linked to English Hospital Episode Statistics. Int $J$ Clin Pract. 2014;68(1):40-48. doi:10.1111/ijcp.12265

7. Shichiri M, Kishikawa H, Ohkubo Y, Wake N. Long-term results of the Kumamoto Study on optimal diabetes control in type 2 diabetic patients. Diabetes Care. 2000 Apr; 23 Suppl 2:B21-9. PMID: 10860187.

8. Srinivasan BT, Jarvis J, Khunti K, Davies MJ. Recent advances in the management of type 2 diabetes mellitus: a review. Postgrad Med J. 2008 Oct;84(996):524-31. doi: 10.1136/pgmj.2008.067918. PMID: 19017837.

9. Dawson KG, Gomes D, Gerstein H, Blanchard JF, Kahler KH. The economic cost of diabetes in Canada, 1998. Diabetes Care. 2002 Aug; 25 (8): 1303-7. doi: 10.2337/diacare.25.8.1303. PMID: 12145225 . 
10. Kornum JB, Thomsen RW, Riis A, Lervang HH, Schønheyder HC, Sørensen HT . glycemic control, and risk of hospitalization with pneumonia: a population-based case-control study. Diabetes Care. 2008 Aug; 31(8): 1541-5. doi: 10.2337/dc08-0138. Epub 2008 May 16. PMID: 18487479; PMCID: PMC2494631.

11. Cengiz E, Xing D, Wong JC, Wolfsdorf JI, Haymond MW, Rewers A, et al., ;T1D Exchange Clinic Network. Severe hypoglycemia and diabetic ketoacidosis among youth with type 1 diabetes in the T1D Exchange clinic registry. Pediatr Diabetes. 2013 Sep ;14(6): 447-54. doi: 10.1111/pedi.12030. Epub 2013 Mar 8. PMID: 23469984; PMCID: PMC4100244.

12. Karges B, Rosenbauer J, Holterhus PM, Beyer P, Seithe H, Vogel C, et al., ; Hospital admission for diabetic ketoacidosis or severe hypoglycemia in 31,330 young patients with type 1 diabetes. Eur $\mathbf{J}$ Endocrinol. 2015. Sep;173(3): 341-50. doi: 10.1530/EJE-15-0129. Epub 2015 Jun 18. PMID: 26088822.

13. Sampson MJ, Dozio N, Ferguson B, Dhatariya K. Total and excess bed occupancy by age, specialty and insulin use for nearly one million diabetes patients discharged from all English Acute Hospitals. Diabetes Res Clin Pract. 2007 Jul; 77(1): 92-8. doi: 10.1016/j.diabres.2006.10.004. Epub 2006 Nov 9. PMID: 17097183.

14. Wang J, Imai K, Engelgau MM, Geiss LS, Wen $\mathrm{C}$, Zhang $\mathrm{P}$; Secular trends in diabetes-related preventable hospitalizations in the United States, 1998-2006. Diabetes Care. 2009 Jul;32 (7): 12137. doi: 10.2337/dc08-2211. Epub 2009 Apr 14. PMID: 19366966; PMCID: PMC2699731.

15. Ajayi EA, Ajayi AO. Pattern and outcome of diabetic admissions at a federal medical center: a 5-year review. Ann Afr Med. 2009 Oct-Dec;8 (4): 271-5. doi: 10.4103/1596-3519.59584. PMID: 20139552.
16. Brown AF, Mangione CM, Saliba D, Sarkisian CA; California Healthcare Foundation/American Geriatrics Society Panel on Improving Care for Elders with Diabetes. Guidelines for improving the care of the older person with diabetes mellitus. J Am Geriatr Soc. 2003 May;51(5 Suppl Guidelines):S265-80. doi: 10.1046/j. 1532-5415. 51.5s.1. x. PMID: 12694461.

17. Hruby A, Hu FB. The Epidemiology of Obesity: A Big Picture. Pharmacoeconomics. 2015 Jul;33 (7): 673-89. doi: 10.1007/s40273-014-0243-X. PMID: 25471927; PMCID: PMC4859313.

18. Forouhi NG, Wareham NJ. Epidemiology of diabetes. Medicine (Abingdon). 2014 Dec; 42(12):698-702. doi: 10.1016/j.mpmed.2014. 09. 007. PMID: 25568613; PMCID: PMC4282306.

19. Wahab NN, Cowden EA, Pearce NJ, Gardner MJ, Merry H, Cox JL, ; ICONS Investigators. Is blood glucose an independent predictor of mortality in acute myocardial infarction in the thrombolytic era? J Am Coll Cardiol. 2002 Nov 20;40 (10): 1748-54. doi: 10.1016/s0735-1097(02)02483-x. PMID: 12446057.

20. American Diabetes Association. 15. Diabetes Care in the Hospital: Standards of Medical Care in Diabetes-2019. Diabetes Care. 2019 Jan;42(Suppl 1): S173-S181. doi: 10.2337/dc19S015. PMID: 30559241.

21. Corsino L, Dhatariya K, Umpierrez G. Management of Diabetes and Hyperglycemia in Hospitalized Patients. 2017 Oct 1. In: Feingold KR, Anawalt B, Boyce A, Chrousos G, de Herder WW, Dungan K, et al., editors. Endotext [Internet]. South Dartmouth (MA): MDText.com, Inc.; 2000-. PMID: 25905318.

22. Diabetes Canada Clinical Practice Guidelines Expert Committee, Malcolm J, Halperin I, Miller DB, Moore S, Nerenberg KA, Woo V,et al., ;InHospital Management of Diabetes. Can J Diabetes. 2018 Apr;42 Suppl 1:S115-S123. doi: 10.1016/j.jcjd. 2017. 10. 014. PMID: 29650083. 
23. Umpierrez GE, Smiley D, Jacobs S, Peng L, Temponi A, Mulligan P, et al., ; Randomized study of basal-bolus insulin therapy in the inpatient management of patients with type 2 diabetes undergoing general surgery (RABBIT 2 surgery). Diabetes Care. 2011;34(2):256-261. doi:10.2337/dc10-1407

24. American Diabetes Association. 14. Diabetes care in the hospital. Diabetes Care.2017, 40, pp. S120S127. http://dx.doi.org/10.2337/dc17-S017.

25. The National Institute for Health and Care Excellence (NICE) guideline [NG28]. Type 2 diabetes in adults: management. Published: 02 December 2015. Last updated: 28th August 2019. Available at: https://www.nice. org.uk/guidance/ng28.

26. Lin W. , Chen C. , Guan H. , Du X. , Li J. Hospitalization of elderly diabetic patients: characteristics, reasons for admission, and gender differences. BMC Geriatr.2016; 16 (1). doi: 10.1186/s12877-016-0333-z.

27. Kefale AT, EshetieTC, Gudina EK Hospitalization Pattern and Treatment Outcome Among Diabetic Patients Admitted to a Teaching Hospital in Ethiopia: A Prospective Observational Study. Journal of Health Medicine.2016; 28 :3441.

28. Akirov A, Diker-Cohen T, Masri-Iraqi H, DuskinBitan H, Shimon I, Gorshtein A;Outomes of hyperglycemia in patients with and without diabetes hospitalized for infectious diseases. Diabetes Metab Res Rev. 2018 Oct;34(7):e3027. doi: 10.1002/dmrr.3027. Epub 2018 Jun 14. PMID: 29774650.

29. Montori VM, Bistrian BR, McMahon MM. Hyperglycemia in acutely ill patients. JAMA. 2002 Nov 6;288(17):2167-9. doi: 10.1001/jama.288.17.2167. PMID: 12413377.
30. Evans NR, Dhatariya KK. Assessing the relationship between admission glucose levels, subsequent length of hospital stay, readmission and mortality. Clin Med (Lond). 2012 Apr;12 (2): 137-9. doi: 10.7861/clinmedicine.12-2-137. PMID: 22586788; PMCID: PMC4954098.

31. Krinsley JS. Association between hyperglycemia and increased hospital mortality in a heterogeneous population of critically ill patients. Mayo Clin Proc. 2003 Dec; 78 (12): 1471-8. doi: 10.4065/78.12.1471. PMID: 14661676.

32. American Diabetes Association. "Diagnosis and classification of diabetes mellitus." Diabetes care vol. 36 Suppl 1, Suppl 1.2013; S67-74. doi:10.2337/dc13-S067.

33. Rains JL, Jain SK. Oxidative stress, insulin signaling, and diabetes. Free Radic Biol Med. 2011 Mar 1;50 (5): 567-75. doi: 10.1016/j.freeradbiomed. 2010.12.006. Epub 2010 Dec 13. PMID: 21163346; PMCID: PMC3557825.

34. Falciglia M, Freyberg RW, Almenoff PL, D'Alessio DA, Render ML. Hyperglycemiarelated mortality in critically ill patients varies with admission diagnosis. Crit Care Med. 2009 Dec;37(12):3001-9. doi: 10.1097/CCM.0b013e3181b083f7. PMID: 19661802; PMCID: PMC2905804.

35. Donnan PT, Leese GP, Morris AD; Diabetes Audit and Research in Tayside, Scotland/Medicine Monitoring Unit Collaboration. Hospitalizations for people with type 1 and type 2 diabetes compared with the nondiabetic population of Tayside, Scotland: a retrospective cohort study of resource use. Diabetes Care. 2000 Dec;23(12):1774-9. doi: 10.2337/diacare.23.12.1774. PMID: 11128351.

To cite this article: Amira M. Elsayed, Ayman M Elbadawy, Walla M. lbrahim, Marwa S. Mahfoz, Rasha O. Abd Elmoniem. Indications and Outcome of Admission of Patients with Diabetes into Benha University Hospitals, Egypt: A Prospective Study. BMFJ 2021;38(1): 266279. DOI: $10.21608 / \mathrm{bmfj} .2021 .49219 .1341$. 
